Research Article

\title{
A Study of the Relationship between the Stress State and Failure Mode of Concrete Specimens
}

\author{
Xinyu Liang $\mathbb{D I}^{1}$ and Faning Dang ${ }^{2}$ \\ ${ }^{1}$ School of Civil Engineering and Architecture, Xi'an Technological University, Xi'an 710021, China \\ ${ }^{2}$ School of Civil Engineering, Xi'an University of Technology, Xi'an 710048, China \\ Correspondence should be addressed to Xinyu Liang; key_xinyu@163.com
}

Received 20 September 2017; Accepted 31 December 2017; Published 15 March 2018

Academic Editor: Yixian Wang

Copyright (c) 2018 Xinyu Liang and Faning Dang. This is an open access article distributed under the Creative Commons Attribution License, which permits unrestricted use, distribution, and reproduction in any medium, provided the original work is properly cited.

\begin{abstract}
An investigation of concrete specimen's strength and its changing mechanism based on numerical simulation of the failure process of axis-stressed concrete specimens with different aspect ratios was described. The state of internal stress and growth of crack of axis-stressed concrete specimens, as well as the changing mechanism of specimen strength under different ambient pressure values, were investigated. The results revealed that specimen strength and failure surface decreased as the aspect ratio is increased. The specimen strength is dependent on the state of internal stress and decreased with decreasing ambient pressure. Additionally, the failure mode shifted from shear failure to tensile failure gradually.
\end{abstract}

\section{General Instructions}

Previous studies have revealed that the strength of concrete is more than a material parameter. A variety of studies on the factors affecting the strength of concrete have been conducted to investigate the changing mechanism of this parameter. Widely studied globally [1-3], concrete can be regarded as a porous composite material consisting of cement mortar, fine aggregates, and coarse aggregates. The nonlinear-inelastic failure of compressed concrete is mainly caused by the growth of voids and microcracks. For industrial applications, the strength of concrete is usually enhanced by increasing the ambient pressure of single-axis compressible concrete, which can retard crack growth and axial compressive strength of concrete. To date, several triaxial tests of concrete have been reported [4-9]. However, these studies focused on the strength of concrete in triaxial tests only and did not investigate the stress-strain relationship under different ambient pressures. Dong et al. [10-17] reported a study of the concrete compression at a fixed ambient pressure.

Among various factors affecting the strength of axisstressed concrete specimens, ambient pressure is one of the key factors. It is challenging to investigate the effect of aspect ratio of concrete strength using computed tomography (CT) due to the limitation of loading equipment. In this article, we prepared compressible concrete specimens with different aspect ratios and investigated the quantity and growth of cracks on these specimens based on numerical simulation. In this way, the strength, failure mode, and state of stress of axis-stressed concrete specimens under different ambient pressures were investigated.

\section{Computational Mode Method}

The numerical calculation in this article was based on random aggregate model establishing approach. The mixing ratio of concrete and parameters of different components are shown in Tables 1 and 2, respectively. The model size is shown in Table 3. Pre-1 to Pre-5 were compression numerical experiments. The aspect ratios $(\kappa)$ of different compression models were $1: 1,1: 2,1: 4,1: 6$, and $1: 10$. The numerical calculation was achieved using a double-brokenline model. In this model, $Z$-direction at the bottom was restrained, and the middle point was perfectly restrained. The formation, growth, and coalescence of cracks were 
TABle 1: The proportion of concrete mixture in Dagang Mountain.

\begin{tabular}{lccc}
\hline Material & Modulus of elasticity, Pa & Poisson's ratio & Tensile strength, Pa \\
\hline Aggregate & $5.8731 E 10$ & 0.1960 & $9.25 E 6$ \\
Mortar & $1.7458 E 10$ & 0.2000 & $2.78 E 6$ \\
Interface & $1.3967 E 10$ & 0.2407 & $1.56 E 6$ \\
\hline
\end{tabular}

TABle 2: The parameters of different compositions of the concrete.

\begin{tabular}{|c|c|c|c|c|c|c|c|}
\hline \multirow{2}{*}{ Strength grade } & \multirow{2}{*}{ Water/cement ratio } & \multirow{2}{*}{ Theoretical bulk density $(\mathrm{kg} / \mathrm{m} 3)$} & \multicolumn{5}{|c|}{ Concrete material consumption } \\
\hline & & & Water & Cement & The fly ash & Sand & Stone \\
\hline R180360 & 0.45 & 2418 & 86 & 134 & 57 & 534 & 1607 \\
\hline
\end{tabular}

TABle 3: The model of the concrete specimens under stress.

\begin{tabular}{|c|c|c|c|c|c|c|c|}
\hline Specimen (model) & & & $-2,-3,-4$ & & & Pull & Bending \\
\hline$(R \times H) \mathrm{mm} /(L \times B \times H) \mathrm{mm}$ & $30 \times 30$ & $30 \times 60$ & $30 \times 120$ & $30 \times 180$ & $30 \times 300$ & $30 \times 120$ & $30 \times 50 \times 150$ \\
\hline
\end{tabular}

TABle 4: Displacement control loading step.

\begin{tabular}{|c|c|c|c|c|c|c|c|}
\hline Model & Pull-1 & Pre-1 & Pre-2 & Pre-3 & Pre-4 & Pre-5 & Bending-2 \\
\hline \multirow{13}{*}{ Displacement load } & 0.01 & 0.01 & 0.08 & 0.16 & 0.16 & 0.16 & 0.01 \\
\hline & 0.03 & 0.012 & 0.12 & 0.28 & 0.28 & 0.2 & 0.02 \\
\hline & 0.06 & 0.016 & 0.16 & 0.4 & 0.36 & 0.24 & 0.03 \\
\hline & 0.08 & 0.022 & 0.2 & 0.52 & 0.44 & 0.28 & 0.04 \\
\hline & 0.10 & 0.028 & 0.28 & 0.64 & 0.52 & 0.4 & 0.05 \\
\hline & 0.12 & 0.04 & 0.34 & 0.76 & 0.60 & 0.76 & 0.06 \\
\hline & 0.13 & 0.052 & 0.4 & 0.88 & 0.68 & 1.14 & 0.07 \\
\hline & 0.14 & 0.064 & 0.52 & - & 0.76 & - & 0.08 \\
\hline & 0.15 & 0.076 & 0.64 & - & 0.84 & - & 0.09 \\
\hline & - & 0.088 & - & - & 0.92 & - & 0.10 \\
\hline & - & - & - & - & 1.0 & - & 0.11 \\
\hline & - & - & - & - & 1.08 & - & 0.12 \\
\hline & - & - & 一 & - & 1.16 & - & - \\
\hline
\end{tabular}

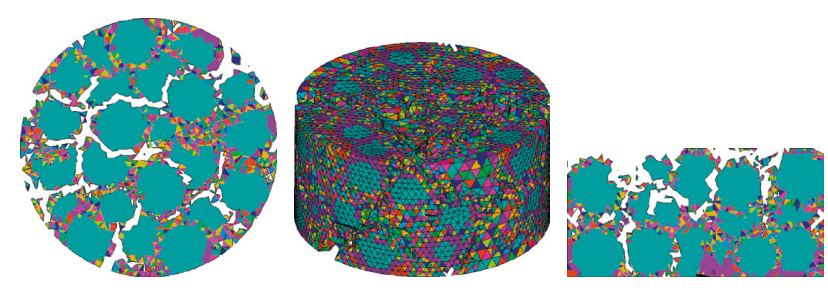

Figure 1: The damaged specimen and damaged cross section of Pre-1.

simulated, and step loading was applied for all models, with displacement control as the loading mode, as shown in Table 4. The study of the states of the concrete specimens with different aspect ratios under stress and failure test.

\subsection{The States of the Concrete Specimens with Different Aspect Ratios under Stress}

2.1.1. Pre-1 Specimen. Figure 1 indicates that Pre-1 specimen with aspect ratio $\kappa$ of $1: 1$ was flat. When the top of the specimen was under stress, confining pressure effect was generated perpendicularly to the stress. Along with the increased axis-stress, the microcracks which were in small

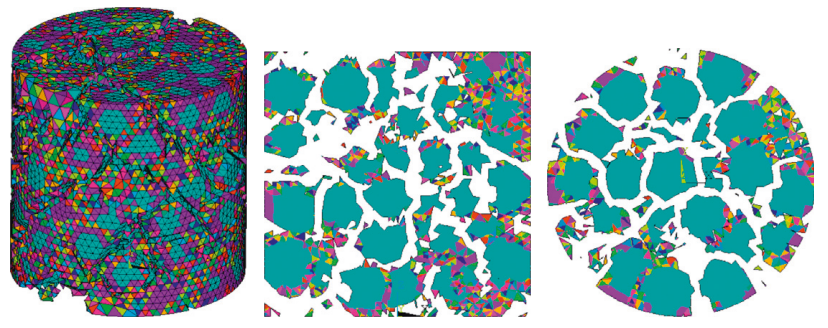

Figure 2: The damaged specimen and damaged cross section of Pre-2.

angles with the axis-stress increased at a higher rate than the microcracks that were in large angles. As the axis-stress increased, the internal cracks formed were almost all parallel to the axis-stress. Therefore, with the increased displacement load, the tension produced from confining pressure increased continuously, forming many intertwined cracks from top to bottom. Finally, the specimen was broken to small pieces.

2.1.2. Pre-2 Specimen. Figure 2 reveals that the concrete specimen exhibited shear-tension damage. This failure mode was similar to that of Pre-1 specimen. The difference is that 

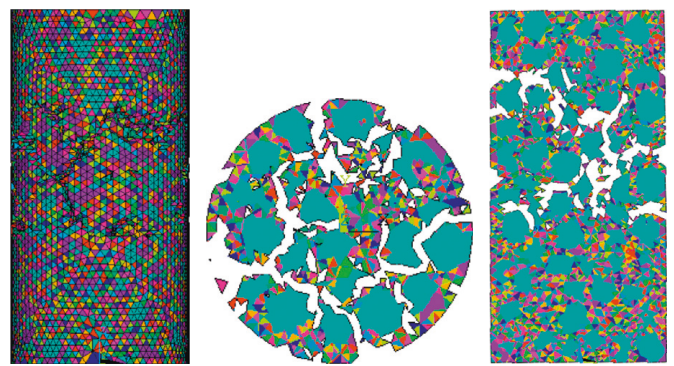

FIgURE 3: The damaged specimen and damaged cross section of Pre-3.
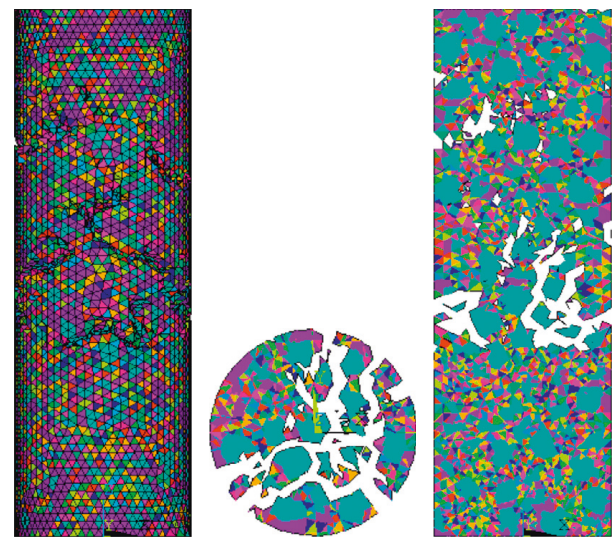

Figure 4: The damaged specimen and damaged cross section of Pre-4.

fewer microcracks were formed. These microcracks induced the subsequently broken of the specimen which resulted in small pieces in the longitudinal section until the complete destruction. As shown in Figure 2, Pre-1 specimen with aspect ratio $\kappa$ of $1: 1$ was flat. When the top of the specimen was under stress, confining pressure effect was formed perpendicularly to the stress. Along with the increased axisstress, the microcracks which were in small angles with the axis-stress increased at a higher rate than the microcracks in large angles. As the axis-stress increased, the internal cracks formed were almost all parallel to the axis-stress. Therefore, with the increased displacement load, the tension produced from confining pressure increased continuously, forming many intertwined cracks from top to bottom. Finally, the specimen was broken to small pieces.

2.1.3. Pre-3 Specimen. Compared with Pre-1 and Pre-2 specimen, as displayed in Figure 3, the internal cracks formed on Pre-3 specimen were far less, and the damaged plane and the horizontal plane were at an angle, not along with the longitudinal direction, which was ascribed to shear failure. In this case, the cracks formed on the damaged plane which was oval and the so-called shear failed plane. The cracks in the damaged interface were $\mathrm{x}$-shaped.

2.1.4. Pre-4 Specimen. As displayed in Figure 4, few cracks formed on Pre- 4 specimen. The cracks went through the damaged plane which was in smaller angle with the cross section. And the damaged area with cracks went through was

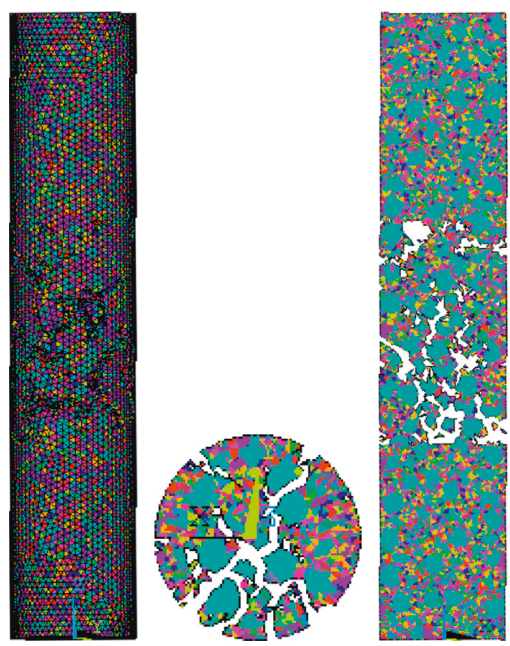

Figure 5: The damaged specimen and damaged cross section of Pre-5.

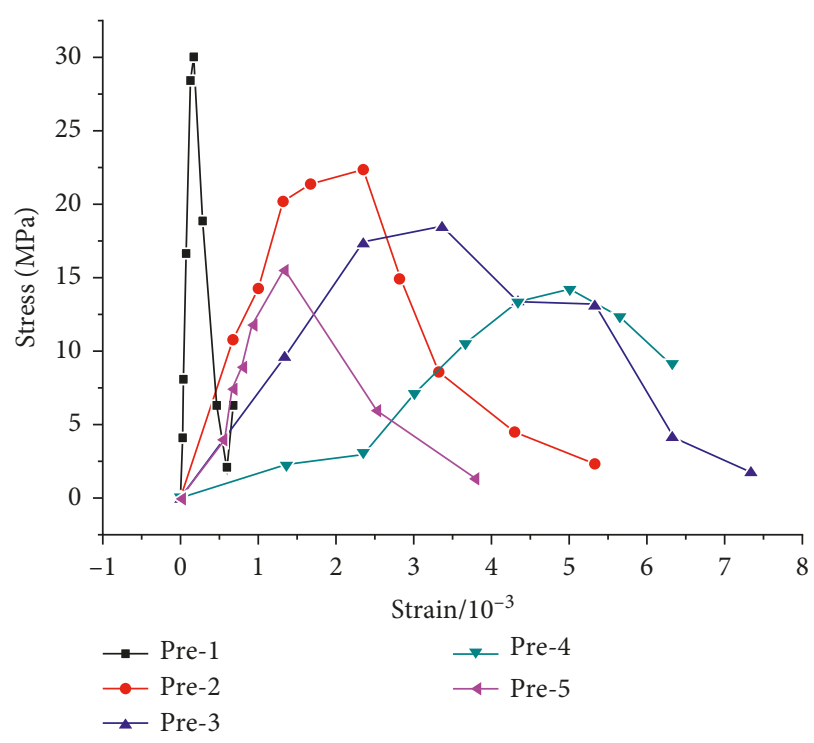

Figure 6: The stress of a certain unit and the strain curve.

obviously less than that of pressure-1, pressure-2, and pressure-3.

2.1.5. Pre-5 Specimen. As displayed in Figure 5, the cracks in Pre-5 specimen were similar and extended straightly along their growth direction. Consequently, the damaged planes with cracks formed tended to be horizontal (-shaped). Besides, the damaged plane was similar to the round plane.

\section{Analysis of the Stress-Strain Curve of the Concrete Specimen with Different Aspect Ratios}

Figure 6 indicates that when the stress on Pre- 1 specimen was below $28.326 \mathrm{MPa}$, the stress changed linearly with the strain. Afterwards, the slope of the stress-strain curve decreased, the interface units and the mortar units started 
damaging, and the damage of elasticity modulus damped. When the stress reached $29.96 \mathrm{MPa}$, the strain increased sharply. In this case, the units were damaged, the specimen strength stopped working, and the strain continued increasing until the failure of the specimen.

When the stress on Pre-2 specimen was below 20.066 MPa, the stress changed linearly with the strain. Afterwards, the slope of the stress-strain curve decreased, the interface units and the mortar units started damaging, and the damage of elasticity modulus damped. When the stress reached 21.23 $\mathrm{MPa}$, the strain increased sharply. In this case, the units were damaged. Then the stress reached its peak at 22.28 MPa, the specimen strength stopped working, and the strain continued increasing until the failure of the specimen.

When the stress on Pre-3 specimen was below 17.30 $\mathrm{MPa}$, the stress changed almost linearly with the strain. Afterwards, the slope of the stress-strain curve decreased, and the interface units and the mortar units started damaging. Along with the damping of the damage of elasticity modulus, the strain increased sharply and the units were damaged. When the stress finally reached its peak at 18.41 $\mathrm{MPa}$, the specimen strength ceased working and the strain continued increasing until the failure of the specimen.

When the stress on Pre-4 specimen was below 20.066 MPa, the stress changed approximately linearly with the strain. Afterwards, the slope of the stress-strain curve decreased, the interface units and the mortar units started damaging, and the damage of elasticity modulus damped. At this point, the strain increased sharply, and the units were damaged. When the stress reached the peak at $14.10 \mathrm{MPa}$, the specimen strength ceased working, and the strain continued increasing until the failure of the specimen.

The maximum stress of Pre-5 specimen obtained from stress-strain curve was $15.38 \mathrm{MPa}$. Before this point, the stress increased with increasing strain whereas, after this point, the stress dropped slowly with increasing strain. Along with enlarged loads, cracks were produced and grown, and the stress was released. Finally, the specimen was destroyed, and the stress was almost completely released.

\section{Analysis of the Stress State of the Specimens with Different Aspect Ratios}

The effect of confining pressure on strength was investigated via computational model. The study on multiphase concrete materials under stress was especially complicated; the relationships between the internal stresses generated on specimens were analyzed in this article. Herein, the central point on the middle cross section was studied. Under the same external force, the axial stress and cyclic stress are basically close to each other. Along with the enlarged aspect ratio of the specimen, the confining pressure decreased step by step. Among them, the confining pressure of Pre-1 specimen was the maximum; $72 \%$ of its axis-stress. Since the stresses in three directions were similar, many vertical and horizontal cracks appeared on Pre-1 specimen, resulting in multiple shear-failure planes and finally small broken pieces. The strain in the units which was stored during the generation and development of the cracks could be released
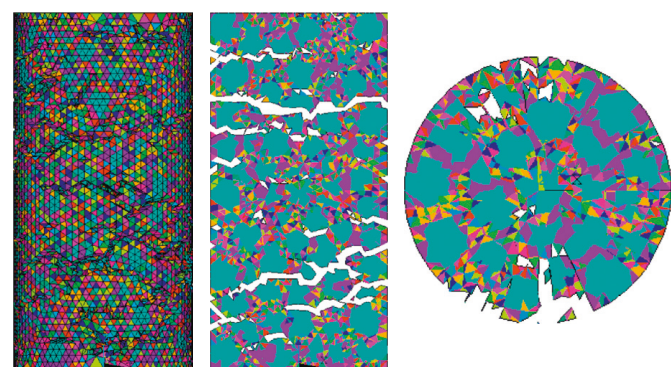

Figure 7: The damage element figure of Pull-1.

along the cracks until the formation of the damaged planes. Pre-1 specimen was broken into small pieces with large exposed surfaces. Along with the enlarged aspect ratios, the rate of confining pressure to axis-stress decreased slowly. At mediate confining pressure, the failure angle of the shearfailure plane was $45^{\circ}$. For Pre- 5 specimen, the effect of confining pressure was negligible and the stress was on monopodium. Besides, the specimen was likely to be damaged along the cross section. In other words, with the increasing aspect ratio of the cylinder specimen, the vertical cracks interlinked with the horizontal cracks and the distribution of the cracks was from dense to sparse. Finally, the vertical cracks turned to horizontal and experienced shear failure and resulted in the development of horizontal cracks and the damage of the cross section. In the formation and development of the cracks, the more the cracks generated, the more the area was damaged.

\section{The States of the Concrete Specimens under Pull}

The maximum tensile strain failure criterion is applied to simulate the tensile process of concrete specimens with displacement control loading. The uniform load is applied on the top surface of the model, and the loading step is divided into nine steps; the displacement load is shown in Table 4.

From Figure 7, concrete specimen tensile action, the stress perpendicular to the tensile stress concentrated easily in the crack tip and crack along its edge began to expand and kept the development in the crack plane. Along with the expansion of the crack, the stress concentration around was also increasing; hence, the development of the crack was not stable, and it extended to the edge of concrete specimens, until the specimen cracking damage. Therefore, the crack shows transverse distribution, perpendicular to the direction of tensile stress, and the crack develops from a main crack until it is destroyed. The failure surface occurs in the cross section of the specimen.

Figure 8 indicates that when stress was less than 5.31 MPa, change in stress with strain was linear, followed by reduction in the change of stress with strain curve slope; damage of part of the interface units and mortar occurred, the elastic modulus was damaged, specimen internal microcracks appeared, and the internal cracks of the specimen rapidly expanded. When the stress reached $7.88 \mathrm{MPa}$, 


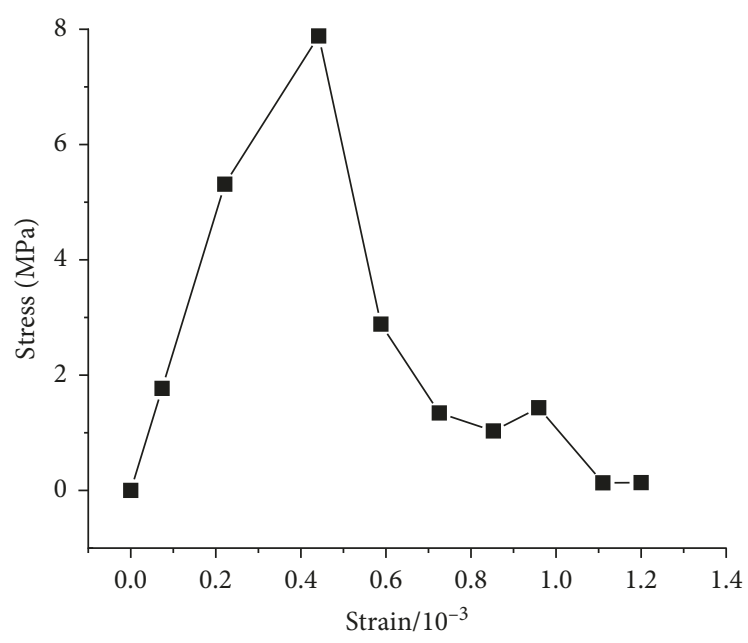

Figure 8: The stress-strain curve of Pull.
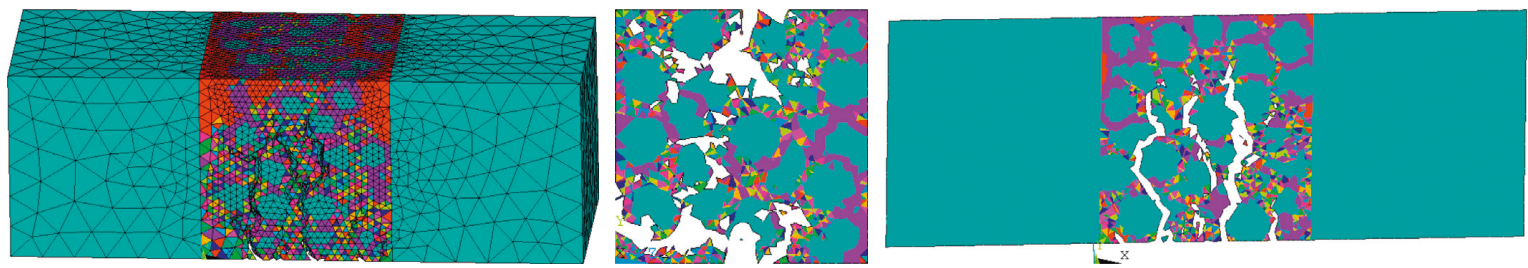

FIGURE 9: The damage element diagram of the bending specimen.

maximum stress, strain was gradually increased. As the crack in the specimen gradually converged and versed, a big crack was formed, stress was rapidly reduced at the same time, damage occurs in the part of the unit, and specimen strength began to fail. As the strain continued to increase, stress stability reduced slowly.

\section{The States of the Concrete Specimens under Bending Simple}

The damage evolution of concrete cube can be seen in Figure 9. In the cube concrete three-point bending test, the maximum bending moment on the cross section is the dangerous point which is farthest from the neutral axis in the uniaxial stress state, the damaged part is the middle part of the cube, the surface tension is one of the largest, and the edge stress of the central section achieves the maximum first. Gradually with the increase of load, cracks extended upward in the longitudinal and cross section of the cube, the effective area of the middle section gradually decreases, and the strength of specimens decreases. When accumulated to a certain degree of the crack damage, specimens are damaged.

Bending simple displacement and stress of the specimens are shown, abscissa for concrete beam specimen edge point on the vertical displacement $v$ divided by the relative displacement of beam height $h$ after $(v / h)$ and the longitudinal axis of the finite element calculation of concrete specimen under the edge point $\mathrm{X}$ to the normal stress. When the displacement of the specimens is $0.617 \mathrm{v} / \mathrm{h} \times 10^{-4}$ before, beam specimens for elastic load, and with the increase of applying displacement when the specimen displacement is $0.84509 v / h \times 10^{-4}$, the stress peak value of the specimen is 6.56 MPa. The specimen cracks are initiated along the lower edge of the section, and the stress decreases with the increase in the displacement. As the displacement continues to increase, the stress decreases significantly. If there is no change in stress with the increase in the displacement, the slope of the stress and displacement curve is almost horizontal, the specimens are damaged, and the concrete beam specimen section is the surface of destruction.

\section{Conclusions}

Numerical simulation was applied to study the performances of concrete specimens with different aspect ratios under continuously increased stress. Along with the increasing stresses, the cracks formed and developed and eventually resulted in the failure of the specimens. The growth direction and the amount of the cracks determined the strength of the specimens, whereas the internal stress determined the development of the cracks. With the increasing aspect ratio, the effect of the confining pressure on the strength of the specimen decreased, and the effect of the constitutive property on the strength enlarged. The strength of the concrete specimens varied with varying confining pressures, which means that the strength was affected by the internal stress. The confining pressure decreased with increasing aspect ratios, and the angle between the damaged plane and the principal stress plane reduced with increasing axis-stress. The specimen was broken into small pieces and 
many shear-failure planes. In this case, the confining pressure, the axis-stress, and the strength of the specimen all reached the maximum. Afterwards, the damaged planes reduced, and the angle between the damaged planes and the cross section also reduced. The change in failure mode was due to decreased internal confining pressure. Along with increased stress, the ability to resist axis-stress weakened as well, resulting in decreased strength of the specimen.

\section{Conflicts of Interest}

The authors declare that they have no conflicts of interest.

\section{Acknowledgments}

This study was supported by Natural Science Basic Research Plan in Shaanxi Province of China (Program nos. 2017JQ5094 and 2017JM5136).

\section{References}

[1] F. E. Richart, A. Brandtzaeg, and R. L. Brown, A Study of the Failure of Concrete Under Combined Compressive Stress, Bulletin No. 185, University of Illinois Engineering Experimental Station, Urbana, IL, USA, 1928.

[2] L. I. Qiang, "Research on damage model of concrete under compression," Master Dissertation, Chongqing University, Chongqing, China, 2006.

[3] W. Ramberg and W. R. Osgood, Description of Stress-Strain Curves by Three Parameters, Technical Note, No. 902, National Advisory Committee for Aeronautics, Washington, DC, USA, 1943.

[4] U. Scholz, D. Nechvatal, H. Aschl et al., Versuch ezum Verhal tenvon Betonun terdreiachsiger Kurzzeit bea nspruchung. Lehrstuhl für Massivbau, Tehnische Universitat München, Deutscher Ausschuss Fuer Stahlbeton, 1992.

[5] D. YuLi, X. Heping, and Z. Peng, "Experimental study and constitutive model of concrete under compression with different strain rate," Journal of Water Conservancy, vol. 7, pp. 72-77, 1977.

[6] P. R. Sparks and J. B. Menzies, "The effect of rate of loading upon the static and fatigue strengths of plain concrete in compression," Magazine of Concrete Research, vol. 25, no. 83, pp. 73-80, 1973.

[7] B. Brester and V. V. Bertero, "Influence of high strain rate and cyclic loading of unconfined and confined concrete in compression C," in Proceedings of 2nd Canadian Conference on Earthquake Engineering, pp. 1-13, Hamilton, ON, Canada, June 1975.

[8] Z. Guo, Strength and Deformation of Concrete, Tsinghua University Press, Beijing, China, 1997.

[9] J. Lu, Theoretical and Experimental Research on Damage Characters of Concrete due to Triaxial Compression, Doctor Dissertation, Dalian University of Technology Dalian, China, 2001.

[10] Y. Dong, H. Xie, and S. Li, "Study of a constitutive model of elasto-plastic damage of concrete inaxial compression test under different pressures," Journal of China Coal Society, vol. 21, no. 3, pp. 265-270, 1996, in Chinese.

[11] N. E. Shanmugam and B. Lakshmi, "State of the art report on steel-concrete composite columns," Journal of Constructional Steel Research, vol. 57, pp. 1041-1080, 2001.
[12] F. Ragueneau and F. Gatuingt, "Inelastic behavior modeling of concrete in low and high strain rate dynamics," Computers and Structures, vol. 81, pp. 1287-1299, 2003.

[13] V. Vydra, K. Trtk, and F. Vodak, "Size independent fracture energy of concrete," Construction and Building Materials, vol. 26, pp. 357-361, 2012.

[14] S. Muralidhara, B. K. Raghu Prasad, H. Eskandari, and B. L. Karihaloo, "Fracture process zone size and true fracture energy of plain concrete from acoustic emission cata-logue," Construction and Building Materials, vol. 24, pp. 479-486, 2010.

[15] L. Xinyu, D. Faning, P. Feng, and T. Hongmei, "CT experimental study on concrete specimens based on the principle of minimum energy," Materials Research Innovations, vol. 19, no. 5, pp. S5-1095-S5-1101, 2015.

[16] M. A. Huai-fa, H.-Q. Chen, and B.-K. Li, "Review on micromechanics studies of concrete," Journal of China Institute of Water Resources and Hydropower Research, vol. 2, no. 2, pp. 124-130, 2004.

[17] F. Dang, Y. Liu, W. Ding et al., "Quantitative analysis of concrete CT images based on damage fracture evolution theory," Chinese Journal of Rock Mechanics and Engineering, vol. 26, no. 8, pp. 1588-1594, 2007. 


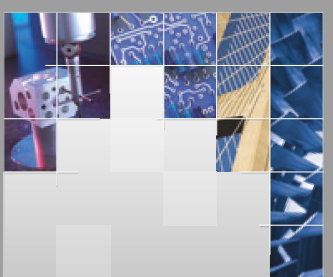

\section{Enfincering}
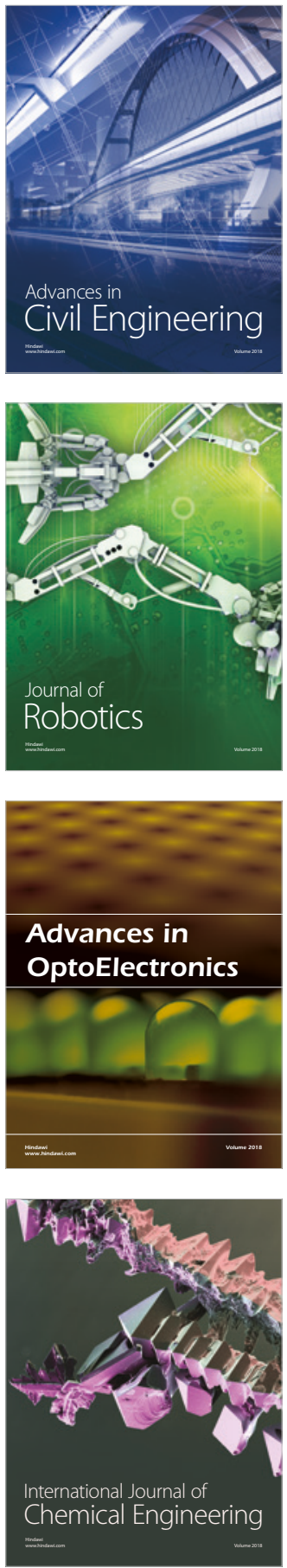

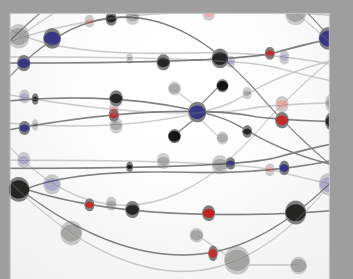

\section{Rotating \\ Machinery}

The Scientific World Journal

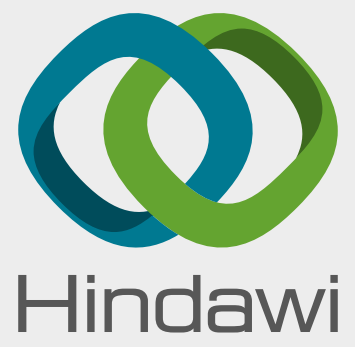

Submit your manuscripts at

www.hindawi.com
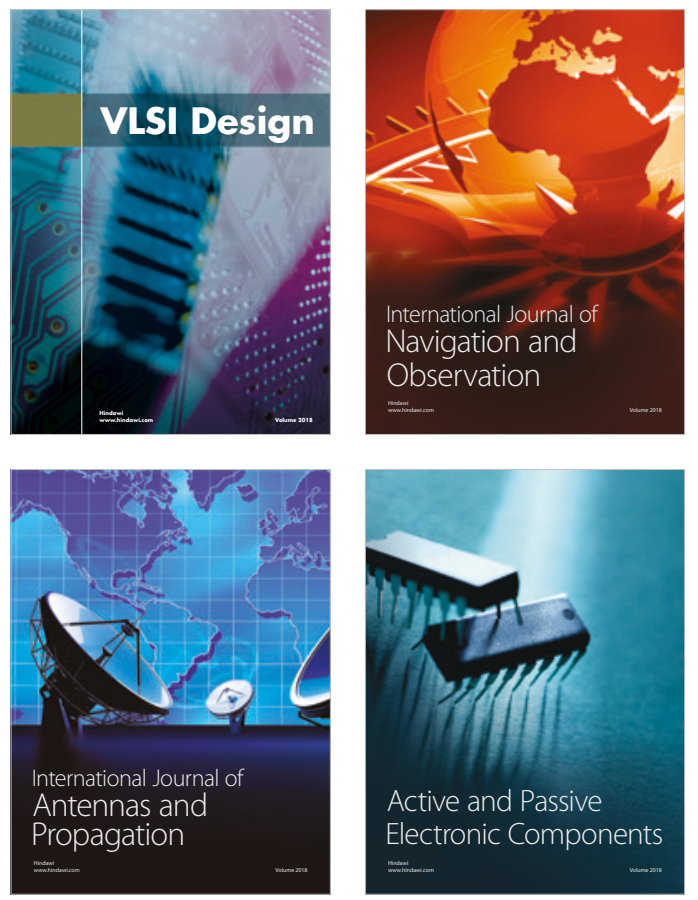
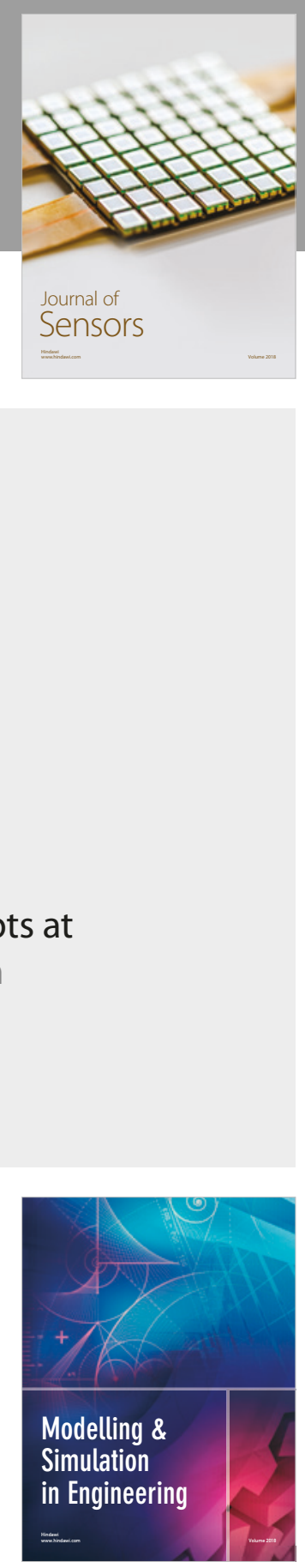

\section{Advances \\ Multimedia}
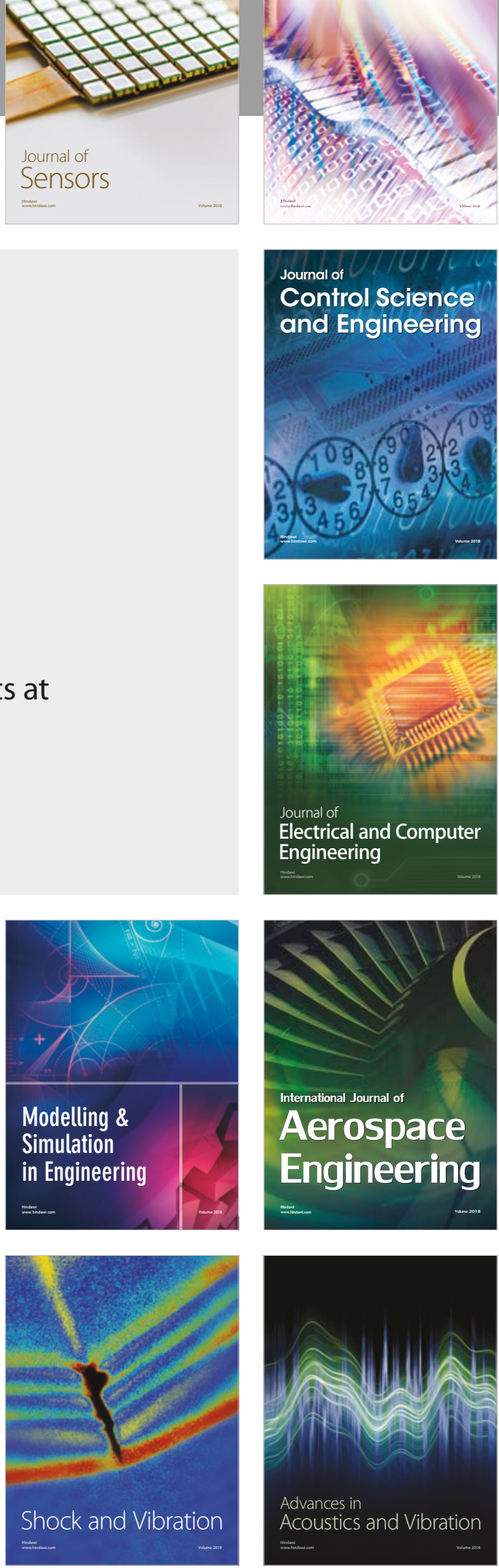